\title{
Pesquisa Qualitativa em Psicologia e Saúde Coletiva: Experimentações com o Recurso Fotográfico
}

Qualitative Survey in Psychology and Collective Health: Experiments with Photographic Resource

Pesquisa Cualitativa en Psicología y Salud Colectiva: Experimentaciones con el Recurso Fotográfico

Maria Aparecida de França Gomes \& Magda Dimenstein

Universidade Federal do Rio Grande do Norte

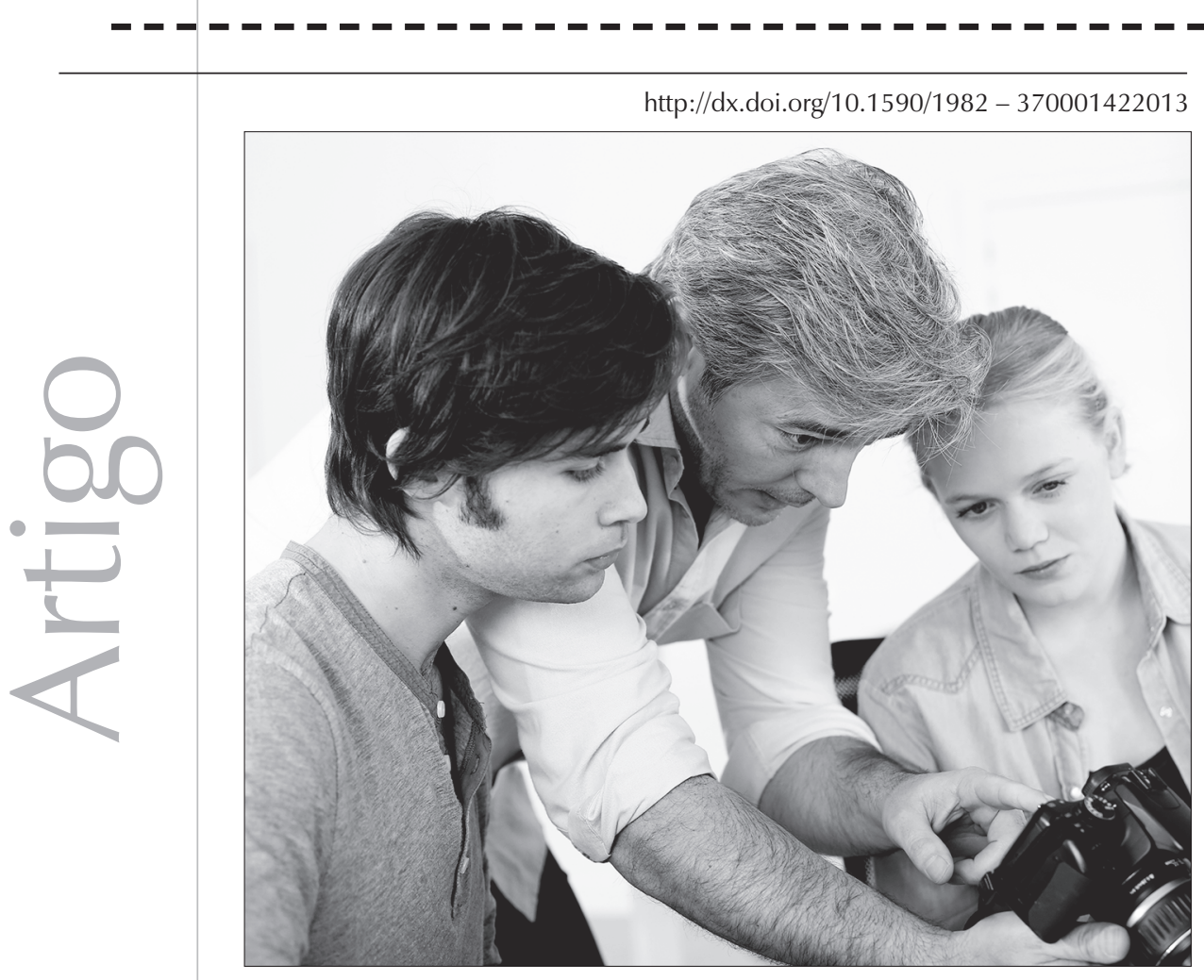


Resumo: A utilização de imagens é um recurso que vem sendo largamente utilizado nas pesquisas qualitativas nas ciências humanas e da saúde. Na Psicologia, as narrativas visuais têm uma função estratégica, pois ajudam a superar barreiras culturais entre pesquisador/pesquisado e produzir conhecimentos culturalmente sensíveis. Objetivou-se apresentar a estratégia de ensaio fotográfico e resultados de investigações que utilizaram narrativas visuais como instrumento metodológico junto às crianças catadoras de lixo, adolescentes em tratamento de dependência química, idosos, adolescentes surdos, profissionais de saúde, estudantes, docentes, assistentes administrativos. Observamos que a fotografia provoca discursos e se apresenta como uma fonte privilegiada de informações da realidade estudada e da visão de mundo dos participantes. A articulação imagem-discurso mostra-se potente no acesso a diferentes dimensões dos sujeitos e constitui uma estratégia de intervenção em várias problemáticas.

Palavras-chave: Psicologia. Saúde coletiva. Pesquisa qualitativa. Fotografia.

Abstract: The use of images is a resource that is widely used in qualitative surveys in human and health sciences. In Psychology, visual narratives have a strategic function since they help overcoming cultural barriers between surveyor/subject and producing culturally sensitive knowledge. One aims at presenting the photographic essay strategy and the findings from analyses that used visual narratives as methodological instrument with waste scavenging children, adolescents under chemical addition treatment, elders, deaf adolescents, health professionals, students, professors, and administrative assistants. We note that photography stirs up discourses and it is presented as privileged source of information from the analyzed reality and of the participants' worldview. The image-discourse articulation shows itself powerful in accessing subjects' different dimensions and it is an intervention strategy in many issues.

Keywords: Psychology. Collective health. Qualitative survey. Photography.

Resumen: La utilización de imágenes es un recurso que viene siendo largamente utilizado en las pesquisas cualitativas en las ciencias humanas y de la salud. En la Psicología, las narrativas visuales tienen una función estratégica, pues ayudan a superar barreras culturales entre investigador/investigado y producir conocimientos culturalmente sensibles. Se objetiva presentar la estrategia de ensayo fotográfico y resultados de investigaciones que utilizaron narrativas visuales como instrumento metodológico junto a niños recolectores de basuras, adolescentes en tratamiento de dependencia química, personas de edad, adolescentes sordos, profesionales de salud, estudiantes, docentes, asistentes administrativos. Observamos que la fotografía provoca discursos y se presenta como una fuente privilegiada de informaciones de la realidad estudiada y de la visión de mundo de los participantes. La articulación imagen-discurso se muestra potente en el acceso a diferentes dimensiones de los sujetos y constituye una estrategia de intervención en varias problemáticas.

Palabras-clave: Psicología. Salud colectiva. Pesquisa cualitativa. Fotografía. 
Este artigo constitui o empreendimento de reunir pesquisas realizadas a partir da utilização do recurso fotográfico segundo a proposta idealizada por Gomes (2002) e Gomes e Dimenstein (2006) denominada ensaio fotográfico. Tal perspectiva foi desenvolvida a partir de uma investigação realizada junto a crianças e adolescentes catadores de lixo, no aterro sanitário de Natal/RN, contribuindo para a pesquisa em Psicologia, bem como para o campo da Saúde Coletiva. Campo aqui é considerado tal como Bosi (2012) faz questão de diferenciar de área: campo comportando uma dimensão política, que "devolve ao espaço científico sua dimensão política, revelando-se, assim, fortemente estratégico para entendermos sua 'economia interna' e as disputas que se expressam em debates conceituais ou metodológicos, mas com reflexos decisivos nos planos político e econômico" (p. 576).

Este ensaio revelou-se como uma estratégia potente de coleta de dados, de inclusão ativa dos participantes, produzindo uma estética visual que mobilizou pesquisadores e pesquisados. Outro resultado importante da utilização da fotografia foi a possibilidade de intervenção que a ferramenta apresentou: pelo efeito de construção, elaboração e reconstrução de signos em cada participante, para além de sujeito da pesquisa, produzindo coautoria no processo de construção do conhecimento.

A partir deste estudo, entre os anos de 2002 e 2012, outras pesquisas utilizando essa estratégia foram realizadas com crianças, adolescentes ouvintes, adolescentes surdos, profissionais de saúde, docentes de Psicologia, técnicos de nível superior, médio, auxiliares de serviços gerais e idosos. Os campos de pesquisa de tais pesquisas compreenderam espaços como o "Lixão", um Centro de Atenção Psicossocial (CAPS), um Hospital Geral, um Shopping Center, um Serviço-Es- cola de Psicologia, comunidades periféricas e espaços diversos como residências e ruas.

Pretendemos com este trabalho ressaltar que a fotografia provoca discursos e se apresenta como uma fonte privilegiada de informações da realidade estudada e da visão de mundo dos participantes. A articulação imagem-discurso mostra-se potente no acesso a diferentes dimensões dos sujeitos e se constitui em uma estratégia de intervenção em várias problemáticas. Dessa forma, as narrativas visuais têm uma função estratégica, contribuindo para superar barreiras culturais entre pesquisador e pesquisado, produzindo conhecimentos culturalmente sensíveis, seja no campo da Psicologia, seja na Saúde Coletiva.

\section{Construindo uma estratégia metodológica na pesquisa em Psicologia e Saúde Coletiva}

Nossos estudos, utilizando a estratégia do ensaio fotográfico, teve como ponto de partida uma pesquisa realizada no início dos anos 2000, como parte de um trabalho de mestrado desenvolvido no Programa de Pós-Graduação em Psicologia (PPGPsi) da Universidade Federal do Rio Grande do Norte (UFRN). Foi com o propósito de abordar a subjetividade enquanto manifestação das condições de vida nos aspectos econômico, social e cultural, que utilizamos o ícone (fotografia) e o signo linguístico (palavra). O signo linguístico tem uma certa hegemonia nas pesquisas qualitativas na Psicologia e na saúde, dessa forma, ao acrescermos o signo fotográfico às possibilidades de leitura e intervenção, pretendíamos acentuar as características de campo e movimento da Saúde Coletiva. Procurávamos desenvolver formas de construção do conhecimento que estivessem alinhadas ao cotidiano. Em outras palavras, buscávamos, de acordo com Bosi (2012), aceitar 
como premissa que as questões de pesquisa vinculam-se aos problemas da existência humana, esse incremento pode ser compreendido também como resposta a certos desafios, em todos os campos do saber e esferas da vida; problemas esses que transcendem as potencialidades do modelo tradicional, no caso da saúde, o modelo da ciência positiva. (p. 576)

Para tanto, inicialmente, fomos buscar bases nos estudos da antropologia visual. Apesar de paradoxal ao nosso intento, os primeiros estudos utilizando imagens guardam um posicionamento positivista, aspecto corroborado por Tacca (2005). Esse estudioso evidencia que as primeiras utilizações da imagem pela antropologia buscavam ser uma tentativa de dar um caráter testemunhal, de objetividade, de neutralidade e de verdade às pesquisas in loco. Para escapar dessas perspectivas, inspiramo-nos nos estudos que valorizam tanto o autor da foto quanto a percepção a respeito das imagens registradas pela própria pessoa, ou seja, nos estudos com perspectiva autofotográfica. Nesses casos, o conteúdo das fotografias pode incluir "qualquer ação, pessoa, objeto, símbolo ou lugar escolhido pelo participante para representar uma ideia ou conceito" (NeivaSilva \& Koller, 2002, p. 238).

Assim, a estratégia por nós adaptada pode ser incluída na categoria de estudo autofotográfico, caracterizado por Ziller e Smith (1977), embora apresentando alterações, pois procuramos articular o signo fotográfico com o signo linguístico e sua incidência nas práticas discursivas. Dessa forma, passamos a denominar a estratégia de ensaio fotografico. Inicialmente, experimentamos na pesquisa Trabalho infantil e risco à saúde: signos produzidos por crianças e adolescentes catadores de lixo em Natal/RN, apresentada em 2002 e resumida por Gomes e Dimenstein
(2005). A partir disso, seis novas pesquisas foram realizadas envolvendo diferentes participantes e problemáticas de estudo: 1. com adolescentes estudando os sentidos de adolescência e risco, realizada por Freitas e Vasconcelos (2004); 2. com adolescentes em um Centro de Atenção Psicossocial álcool e drogas (CAPS ad), estudando os sentidos de adolescência e tratamento, apresentada por Freitas (2010); 3. com adolescentes surdos nas temáticas de sexualidade e adolescência, apresentada por Silva e Oliveira (2011); 4. com profissionais de saúde em uma unidade de terapia intensiva (UTI) de um hospital geral, na temática humanização e acolhimento, apresentada por Medeiros e Bezerra (2011); 5. com idosos sobre os sentidos de velhice e sexualidade, apresentada por Pereira e Sales (2011); e, por último, sobre a história de um Serviço-Escola de Psicologia apresentada por Penha e Lima (2012).

Esses estudos revelaram que a estratégia do ensaio fotográfico apresenta como pontos positivos o estímulo à produção de narrativas e o favorecimento da aproximação entre participantes e pesquisadores, como evidenciado na seguinte fala de uma participante: já que você deu a máquina pra mim tirar [a fotografia] ! - Aí eu digo: então eu tô vendo que elas são pessoa boa. (Freitas \& Vasconcelos, 2004, p. 63). Ainda de acordo com as autoras, a estratégia também possibilita a "implicação do sujeito no discurso fazendose produzir novos signos" (p. 64). Outro aspecto destacado da estratégia foi a pertinência para a pesquisa junto à crianças e idosos, proporcionando uma aproximação e facilitação na produção de dados, gerando oportunidade de empoderamento dos participantes, no que se refere aos saberes produzidos por eles próprios. Ademais, Silva e Oliveira (2011) acentuam a relevância do uso da fotografia conjugado à produção de sentidos especialmente com a população surda, por 
não restringir-se ao simples registro do real, mas significar uma forma alternativa de linguagem em pesquisa, tendo caráter facilitatório no sentido de possibilitar a realização de apontamentos em relação aos signos escolhidos por meio de verbalizações. Ao considerarmos a experiência visual do surdo nas formas de relacionar-se com o mundo, tal ferramenta metodológica revelou-se bastante pertinente, por operar notavelmente sobre esta especificidade. (p. 71)

O que aqui denominamos estratégia de ensaio fotográfico extrapola o sentido restrito de técnica, pois considera, além do fato de servir como um procedimento de coleta de dados, uma conjugação de conceitos e princípios que se coadunam à produção de conhecimento a partir de uma confluência de saberes que alude à "inter(trans)culturalidade" (Bosi, 2012, p. 580), inclusive e principalmente, ao saber popular de variadas pessoas, contextos e etapas de vida. Para Bosi (2012), a Pesquisa Qualitativa em Saúde tem o desafio de convidar não apenas à interdisciplinaridade convocando a uma ampliação das discussões em pesquisa, para além das disciplinas, mas considerando outras contribuições e saberes, como a fotografia, cinema, entre outros.

As investigações que fizeram uso da estratégia do ensaio fotográfico contaram com o total de 83 participantes até o ano de 2012. A seguir, detalharemos seu formato e emprego nas várias temáticas.

\section{Ensaio fotográfico: construções e adaptações necessárias}

O ensaio fotográfico enquanto ferramenta de pesquisa consiste na interlocução de saberes de áreas como Semiótica, Antropologia, Psicologia, Saúde Coletiva, Sociologia, História, Geografia, Linguística, Psicanálise,
Artes, entre outras. À função referencial e cognitiva acrescem-se as dimensões poética, estética e ética. Sobre o uso de fotografias em procedimentos de coleta de dados nas pesquisas em ciências humanas, destaca-se o ensaio autofotográfico. Em Psicologia, um dos primeiros estudos registrados no Brasil foi realizado em uma pesquisa com crianças em Fortaleza, realizada por Monteiro e Dorllinger (1996), os quais se inspiraram no método de Ziller (1977). Esse método consiste no pesquisador disponibilizar uma câmera fotográfica ao participante da pesquisa, após entrevista e explicação do manuseio da máquina, solicita que este tire fotografias que façam uma descrição dele próprio, gerando a "autofotografia" (Monteiro \& Dorllinger, 1996).

$\mathrm{Na}$ primeira pesquisa realizada por nós (Gomes, 2002; Gomes \& Dimenstein, 2005), utilizamos a câmera fotográfica para que crianças e adolescentes registrassem, no local em que catavam lixo, algumas imagens que lembrassem categorias dadas previamente por nós. Vale ressaltar que não tivemos acesso a qualquer trabalho que utilizasse esse procedimento, ou seja, que tenha feito uso da produção fotográfica realizada pelos próprios sujeitos de pesquisa a partir de categorias anteriormente fornecidas pelo pesquisador. Por isso, foi necessária uma adaptação dos procedimentos usados nas pesquisas em antropologia visual e no "ensaio autofotográfico" de Monteiro e Dorllinger (1996) e Ziller (1977).

Neiva-Silva e Koller (2005) realizaram levantamento dos principais indicadores das vantagens da utilização da fotografia nas pesquisas em Psicologia, ressaltando a facilitação do rapport entre pesquisador e sujeito, a simplicidade do processo, a "riqueza de conteúdos" proporcionando "entusiasmo" aos participantes, aspectos observados também nas pesquisas com ensaio fotográfico na 
nossa realidade. Como desvantagem, as autoras destacaram a dificuldade em encontrar "pessoas, cenas ou objetos apropriados para representar os diferentes conceitos" e a quantidade reduzida de participantes, como também apontadas por Dinklage e Ziller (1989), aspectos que não compartilhamos em função da facilidade do acesso aos participantes e da adesão à proposta observada em nossas pesquisas de campo.

O ensaio fotográfico pode ser considerado parte central do procedimento do que denominamos, a partir de Bosi (2012, p. 580), como "produção negociada de evidências", termo que vem substituir o conhecido "COleta de dados". No ensaio fotográfico a participação do pesquisador se dá de forma intensa, principalmente na escolha de categorias que originarão signos que motivarão o ensaio feito pelos participantes. Baseadas em Kossoy (2000), concebemos o processo da fotografia e suas relações com a realidade como uma "representação resultante do processo de criação/construção do fotógrafo" (p. 30). Na nossa proposta do ensaio fotográfico, há uma construção conjunta, na qual a imagem fotográfica, o assunto (recorte temporal) é proposto pelo pesquisador e a interrupção temporal (fotografia) é realizada pelos sujeitos, a quem denominamos participantes (Gomes \& Dimenstein, 2005).

\section{Da palavra às fotos, das fotos aos discursos: o passo a passo da pesquisa utilizando o ensaio fotográfico}

Após a definição dos objetivos do estudo, o pesquisador precisa escolher o(s) signo(s) que serão os norteadores das fotografias. Essa escolha está relacionada diretamente ao problema de pesquisa e aos objetivos da investigação. São signos que se sustentam na análise dos elementos que compõem o campo problemático e a literatura especiali- zada, fundamentando essas escolhas. O tempo destinado à pesquisa de campo, a imersão na pesquisa, o local do estudo, a quantidade de participantes são balizadores para a escolha da quantidade de signos.

O uso de signos iniciais ou preestabelecidos em um projeto de trabalho dá origem, durante a execução da pesquisa, a novas categorias, que serão norteadoras no processo de análise dos dados. A abordagem discursiva utilizada na presente proposta de trabalho trata os discursos e as fotografias como formas sociais de ação e produção de sentidos sobre os eventos da vida (Spink \& Menegon, 2000), ou seja, as pessoas empregam algumas categorias para legitimar a ideologia, mas também podem, a partir da fala, recriar o cotidiano, dando-Ihe outros sentidos, podendo, a partir de novas combinações, gerar questionamento em oposição à legitimação apontada. Para nós, esse processo promove intervenções na vida das pessoas.

Spink e Menegon (2000) afirmam ainda que as descrições categoriais apresentam a possibilidade de expor o posicionamento de quem fala. $\mathrm{O}$ emissor utiliza categorias de maneira reflexiva e "na conversa, as pessoas podem usar categorias a partir dos usos habituais, pautadas pelo uso do sentido mais hegemônico e cristalizado; podem, entretanto, usá-las em novas combinações, gerando espaço para controvérsias" (p. 81). Ao longo desses doze anos, foram pesquisados diferentes signos: saúde, doença, infância, trabalho, risco, adolescência, tratamento, sexualidade, família, velhice, acolhimento, humanização, história e SIP (Serviço Integrado de Psicologia).

Sobre o passo a passo da produção negociada de evidências (Bosi, 2012), resumiremos o que já descrevemos em Gomes e Dimenstein (2005) por ocasião de nossa primeira publicação sobre a estratégia que ora 
discorremos. Dividimos os procedimentos da pesquisa em três períodos distintos, os quais denominamos Fase 1, Fase 2 e Fase 3.

A Fase 1 é caracterizada pelos aspectos exploratórios ou de conhecimento do campo de pesquisa escolhido que inclui o(s) problema(s), o local e a realidade social envolvida. Após a definição do local e dos objetivos do estudo, realizamos uma visita para conhecer a área/território e, caso necessário, contatar informantes-chave. Tudo começa com a apresentação do pesquisador e do interesse deste em estudar o campo escoIhido; em seguida, apresentamos mais detalhadamente o projeto de pesquisa: objetivos, condução, os signos que temos a intenção de pesquisar, instrumentos de coleta das informações (roteiro de entrevista e fotos). Nessa ocasião, perguntamos se a pessoa contatada pode participar de um ensaio (piloto) da pesquisa. A entrevista pode ser gravada ou filmada caso haja o consentimento tal como ocorreu no estudo com adolescentes surdos. Os instrumentos utilizados nessa fase foram: câmera fotográfica, gravador de voz ou filmadora, roteiro de entrevista, papel ofício, caneta e prancheta. Essa fase proporciona mais familiaridade com o manuseio dos instrumentos de trabalho, ajustes no roteiro de entrevista semiestruturada e treino no procedimento de entrevista, como a explicação sobre o funcionamento da câmera, processo de tomada das fotografias e instruções em geral.

A Fase 2 tem início com a produção negociada das evidências propriamente ditas. Apresentamos as ferramentas de trabalho, explicamos o uso destas, solicitamos que o participante produza a(s) fotografia(s) e damos seguimento com a entrevista inicial. Nessa fase, além da observação participante, são realizados o ensaio fotográfico e a primeira entrevista com a caracterização mais detaIhada dos participantes, ou seja, os dados sociodemográficos. A seguir, perguntamos se alguma vez o sujeito já fotografou. Independentemente da resposta, damos alguma explicação sobre o processo de fotografar. Primeiro, apresentamos a câmera; em seguida, suas partes essenciais (visor, botão de disparo para captação da imagem, foco ou visualização na câmera digital), esclarecemos que imagens muito distantes não são captadas pelo tipo de câmera simples geralmente utilizada, oferecemos exemplo de distância de coisas ou paisagens que pretendemos que apareçam nítidas na foto (distância para aparecer o corpo inteiro de uma pessoa ou apenas parte do corpo, objetos, etc.); por último, damos a dica para que o participante prenda a respiração na hora de apertar o botão de disparo para a captação da imagem sem tremores.

Após fornecermos os dados sobre o instrumento, solicitamos que o participante faça uma fotografia a partir de uma ou mais palavras (signo), esclarecendo que, posteriormente, em outro dia a combinar, as fotos serão trazidas (reveladas ou impressas) para ele/ela ver e falar sobre estas. Inicialmente, anunciamos todos os signos e perguntamos por qual ele(a) gostaria de iniciar e, assim, vamos lembrando o restante, caso seja solicitado. Após cada foto, perguntamos o que foi fotografado, anotamos junto com o número da foto (obedecendo à sequência do filme na câmera analógica ou das fotos na câmera digital), para podermos confeccionar os painéis.

Por último, no terceiro período ou Fase 3 , são produzidos os discursos pelo par- 
ticipante, tendo como ponto de partida a(s) fotografia(s) produzida(s) na Fase 2 . A Fase 3 é a fase de retorno ao campo após a revelação ou impressão das fotografias para apresentação da produção fotográfica. Aqui, solicitamos que cada um discorra sobre sua produção e sobre o(s) signo(s) que thes deram origem. Para isso, são confeccionados painéis nos quais as fotografias de cada participante são colocadas. No verso, escreve-se o nome, a idade do participante e o número de cada foto, de acordo com a ordem da máquina fotográfica (filme). Essas informações não ficam visíveis aos participantes.

Uma observação que não podemos deixar de registrar é sobre a importância da antecipação da foto aos discursos sobre os signos dados. Nesse ponto, partimos do que Rosolato (1988) chamou de desconstrução da "ideologia verbo-cêntrica" (p. 67), sem ignorar o campo da comunicação não verbal, mas também Ihe dando lugar. É a consideração de outros signos, além do linguístico como portadores de mensagem e dessa forma, mediando falas, comunicando.

\section{Algumas experiências de pesquisa com ensaio fotográfico}

Nosso objetivo nessa parte é trazer uma amostra de estudos que utilizaram a proposta de ensaio fotográfico de Gomes (2002) e de Gomes e Dimenstein (2005). Pesquisas que utilizaram signos idênticos - adolescência e sexualidade - com populações diferentes serão apresentadas na perspectiva de ressaltar as potencialidades da ferramenta nos estudos e pesquisa em ciências humanas e da saúde. Essas pesquisas evidenciaram a conjugação de fotografias e narrativas que corrobora- ram o ideal social e aquelas que escaparam desse padrão. Ou seja, o que essas fotos dizem de infância, adolescência, trabalho, saúde, doença, risco, tratamento, sexualidade, velhice, humanização? Sobressaem componentes tanto compartilhados pela cultura quanto conteúdos singulares a cada modo de ver e viver no cotidiano.

\section{O signo adolescência}

O signo adolescência por meio de ensaio fotográfico foi pesquisado em três trabalhos distintos. Da rua ao shopping, da moradia aos espaços de consumo, da quadra de esportes ao comércio, diferentes realidades conectadas ao signo foram reveladas. $\mathrm{O}$ ensaio fotográfico viabilizou a produção do novo, do inusitado, mostrou a derrocada de padrões estabelecidos nos achados de pesquisas, sempre surpreendendo os pesquisadores e os participantes. As pesquisas aconteceram como uma produção de conhecimentos e encontros. No entanto, a imagem fotográfica por si só não revelava a realidade, demandando dos pesquisadores questionamentos e busca de sentidos também por meio dos discursos, como apontaram Silva e Oliveira (2010), referindo-se à produção da pesquisa com adolescentes surdos, realizada por elas, como uma "encruzilhada do dito e do não dito, na qual se estabeleceram os mais singelos encontros" (p.105).

Sobre o signo "adolescência", constatou-se que há concepções que se conformam ao ideal social contemporâneo de conceber a adolescência enquanto período em que se busca estar próximo ao grupo, ao outro (Freitas, 2010). Nesse sentido, foram fotografados locais de circulação de atividades coletivas ou grupos de pessoas jovens. Para ilustrar que não existem concepções universais, em dois dos três estudos com adolescente, um adolescente fotografou outro sozinho. 


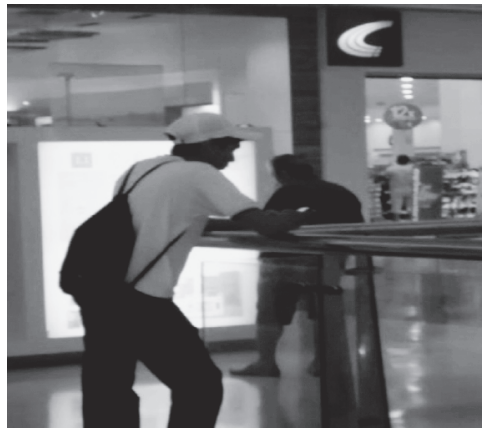

"A foto de Patrícia, 15 anos, foi um dos poucos registros relacionado à categoria adolescência que retratam um adolescente sozinho. (Foto 1) Isto nos remete à concepção bastante apregoada do sentimento de desvinculação e alienação associado ao adolescer, visto também enquanto período de isolamento e solidão. Momento impreciso, de retomada da "bagagem" trazida da infância, de procura por si mesmo (Charbonneau, 1980". (Silva \& Oliveira, 2011, p. 78)

Figura 1. Fotografia de Adolescência por Patrícia, 15 anos. Fonte: Silva, G. O. \& Oliveira, R. F. (2011). Escutando a surdez: signos e produção de sentidos por adolescentes surdos. (p. 79). Trabalho de Conclusão de Curso, Curso de Psicologia, Universidade Potiguar Laureate International Universities, Natal.

A adolescência, para alguns dos participantes, apresentou-se, enquanto condição, como possibilidade de realização, como ação, desmistificando a noção de fenômeno natural relativo a uma faixa etária determinada, como apresentam as teorias psicológicas sobre o assunto. Por outro lado, outras fotografias e discursos produzidos pelos adolescentes confirmam o que asseveram as teorias (Gomes, 2002; Vasconcelos \& Oliveira, 2004; Freitas, 2010; Silva \& Oliveira, 2011). Abaixo, apresentaremos ilustração de fotografias e discursos que corroboram com o ideal social e científico (figuras, 2 e 3).

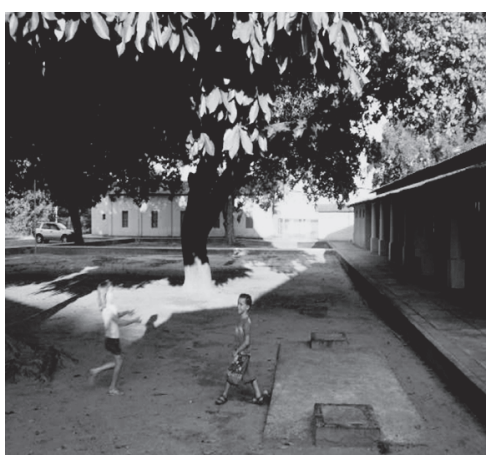

A Figura 2 "traz um traço cultural importante no sentido de adolescência. Trata-se do encontro entre duas crianças, um menino e uma menina que brincam nas instalações do CAPS, que para o adolescente tem o sentido de tempo de viver (J., masculino, 13 anos). O sentido atribuído à adolescência traz o que a literatura apresenta como sendo um sentimento moderno, ou primeiro adolescente (Ariès, 2006 ). (Freitas, 2010, p. 37)

Figura 2. Fotografia de adolescência por J, masculino, 13 anos. Fonte: Freitas, J. L. (2010). Os signos "adolescência" e "tratamento" através da percepção dos adolescentes usuários de substâncias psicoativas. (p.38) Trabalho de Conclusão de Curso, Curso de Psicologia, Universidade Potiguar - Laureate International Universities, Natal, RN.

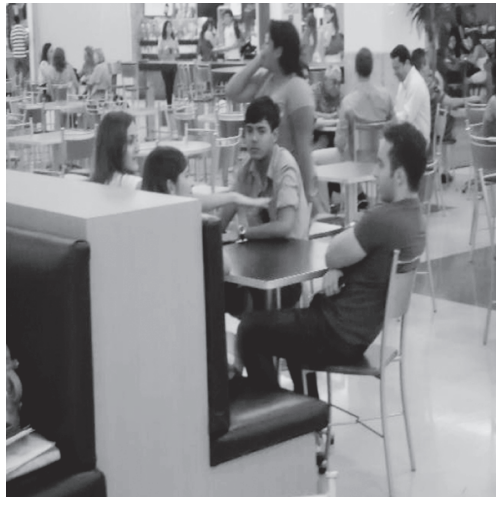

“(...) o participante capturou o momento exato em que uma adolescente utiliza-se de uma expressão corporal colocando em evidência uma das mãos numa atitude comunicativa que conta com os olhares atentos de quem está à sua volta". (Silva \& Oliveira, 2011, p.77)

Figura 3. Fotografia de adolescência por Eduardo, 17 anos. Fonte: Silva, G. O. \& Oliveira, R. F. (2011). Escutando a surdez: signos e produção de sentidos por adolescentes surdos. (p. 77). Trabalho de Conclusão de Curso, Curso de Psicologia, Universidade Potiguar - Laureate International Universities, Natal, RN. 
Alguns discursos e fotografias fogem ao padrão de adolescência acima referido, conforme observado por Freitas (2010): "Outros sujeitos produziram discursos e fotos incomuns. Não usaram os signos, brincar, trabalhar em seus discursos. Apontam para uma adolescência marcada por muitas vicissitudes tais como uso de drogas, violência, o não acesso à escola, ao lazer" (p. 38).

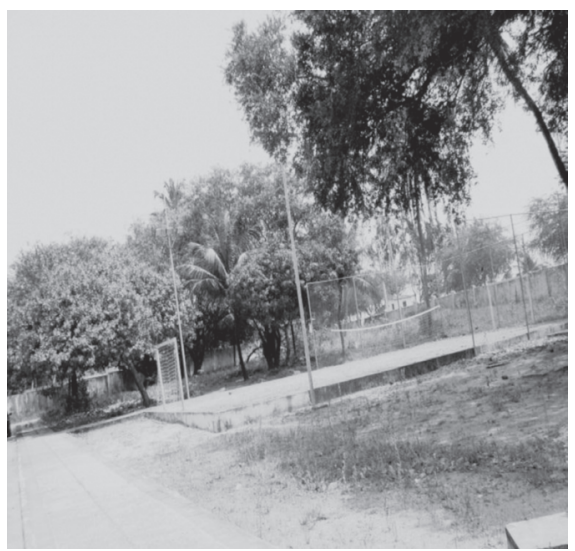

M. justifica a foto do campo dizendo que se trata de um espaço muito utilizado pelos adolescentes em tratamento, diz ele: é o que a gente mais faz lá, jogar bola'. O que chama atenção na fala de M. é que conforme obser-vado durante a pesquisa e em outras situações em que $O$ pesquisador estava no CAPS, eles não fazem uso desse espaço. Dito de outra forma, adolescência enquanto fase do desenvolvimento humano é um conceito construído historicamente na Modernidade e que se torna um ideal cultural no momento atual, ao qual o sujeito adolescente se identifica, mas que não corresponde com o seu desejo. (Freitas, 2010, p. 40)

Figura 4. Fotografia de adolescência por M., masculino, 13 anos. Fonte: Freitas, J. L. (2010). Os signos "adolescência" e "tratamento" através da percepção dos adolescentes usuários de substâncias psicoativas. (p.40) Trabalho de Conclusão de Curso, Curso de Psicologia, Universidade Potiguar Laureate International Universities, Natal, RN.

\section{O signo sexualidade}

O signo sexualidade foi pesquisado em dois trabalhos, um com adolescentes surdos e outro com idosos. No estudo com idosos, a sexualidade foi fotografada e assim percebida como sendo o próprio idoso, bem como representada por árvores que trazem recordações e, assim, representa algo que já passou.

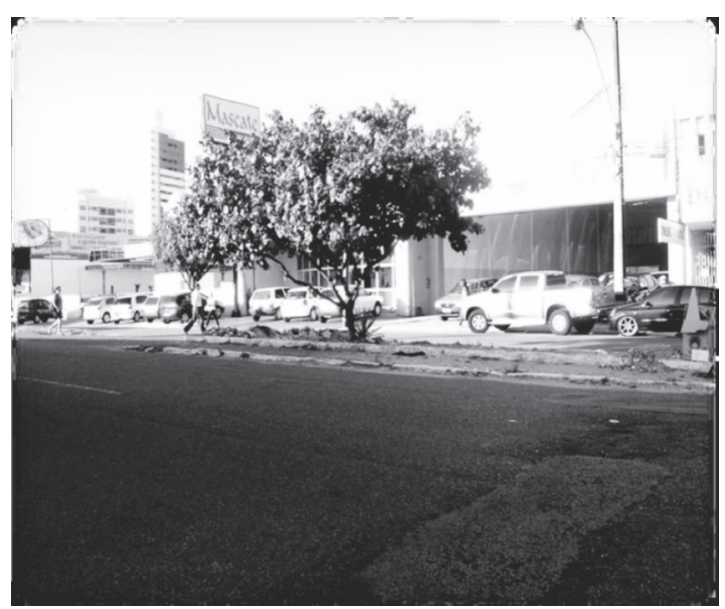

Foi isso que eu entendi, que sexualidade a pessoa vem ao mundo através do sexo, não é? Aí a planta vem do pé através da semente. Foi o que eu entendi. (Clarice, 61anos.) (Pereira e Sales, 2011, p. 69). A sexualidade representada associada à capacidade reprodutiva, à concepção.

Figura 5. Fotografia de sexualidade por Clarice, 61 anos. Fonte: Pereira, E. L. \& Sales, F. G. de M. (2011). (Re)tratando a velhice e a sexualidade na terceira idade: um registro fotográfico. (p.69) Trabalho de Conclusão de Curso, Curso de Psicologia, Universidade Potiguar Laureate International Universities, Natal, RN. 


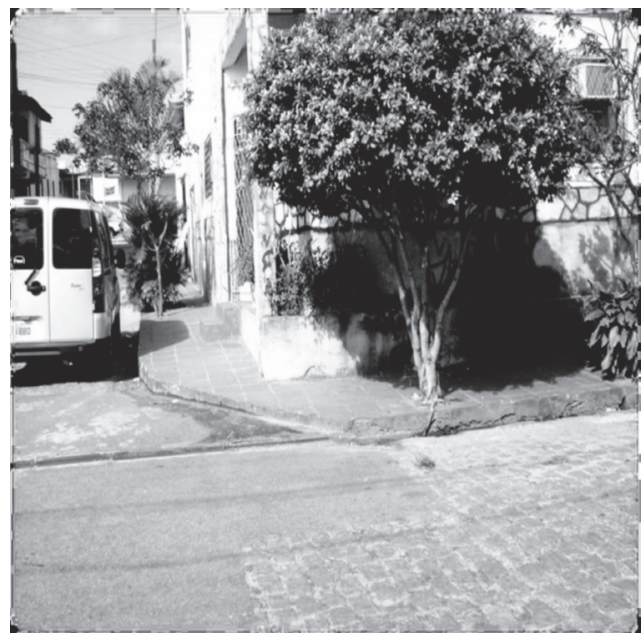

"Sexualidade era que... Eu entendia assim quando nascia uma criança se fosse homem... Dizia assim: Qual é o sexo da criança? É menino e da menina era menina"( Zila, 84 anos. In Pereira \& Sales, 2011, p. 70)

E aqui relembra minha juventude que eu gostava de conversar com a pessoa amada embaixo do pé de pau. (...) vejo nessa foto o tempo que eu era jovem, que gostava de conversar com minhas colegas, com a pessoa que eu amava ele eu relembro esse dia... sabe?" (Zila, 84 anos). (Pereira \& Sales, 2011, p. 75).

Figura 6. Fotografia de sexualidade, por Zila, 84 anos. Fonte: Pereira, E. L., \& Sales, F. G. de M. (2011). (Re)tratando a velhice e a sexualidade na terceira idade: um registro fotográfico (p. 75). Trabalho de Conclusão de Curso, Curso de Psicologia, Universidade Potiguar - Laureate International Universities, Natal, RN.

A sexualidade como uma árvore, assim apresentada por mais de um idoso no registro fotográfico, traz diversas produções discursivas ultrapassando a pretensa objetividade da fotografia - apontada em algumas tendências na utilização de imagens em pesquisa -, mas construindo o diverso a partir delas: serve ao discurso para representar a reprodução, o prazer, ultrapassando a representação apenas da cópula presente em alguns discursos.

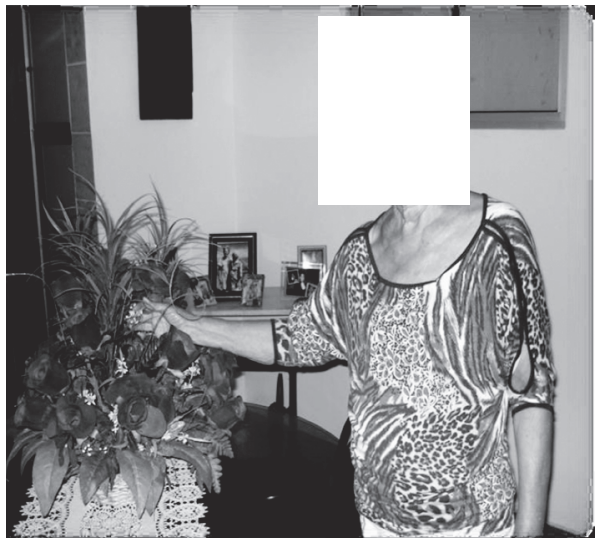

"Sexualidade, o que veio na minha cabeça foi isso: A sexualidade no sexo, fazer sexo e a sexualidade viver... a pessoa ser sexy, viver bem... eu acho assim." (Cecília, 73 anos) (Pereira \& Sales, 2011, p. 71).

Figura 7. Fotografia de Sexualidade - Cecília, 73 anos. Fonte: Pereira, E. L. \& Sales, F. G. de M. (2011). (Re)tratando a velhice e a sexualidade na terceira idade: um registro fotográfico (p. 71). Trabalho de Conclusão de Curso, Curso de Psicologia, Universidade Potiguar - Laureate International Universities, Natal, RN. logia, Universidade Potiguar Laureate International Universities, Natal, RN.

Tanto as fotografias quanto os discursos produzidos pelos idosos apresentam a sexualidade viva. A ideia de que no idoso a sexualidade ficou para trás é contestada por várias das produções dos participantes da pesquisa. Outro estudo incluindo o signo sexualidade foi realizado com adolescentes surdos. As pesquisadoras optaram por fazer a análise dos dados articulando os signos família e sexualidade. A conclusão é de que os sentidos que mais se destacaram de sexualidade apresentaram-se singulares, incomuns, considerando outras pesquisas na área (Silva \& Oliveira, 2011).

A semelhança entre esses dois estudos citados - com adolescentes e idosos - é a concepção de longevidade da sexualidade. Entre adolescentes, ela foi representada como algo que só tem fim com a morte. 

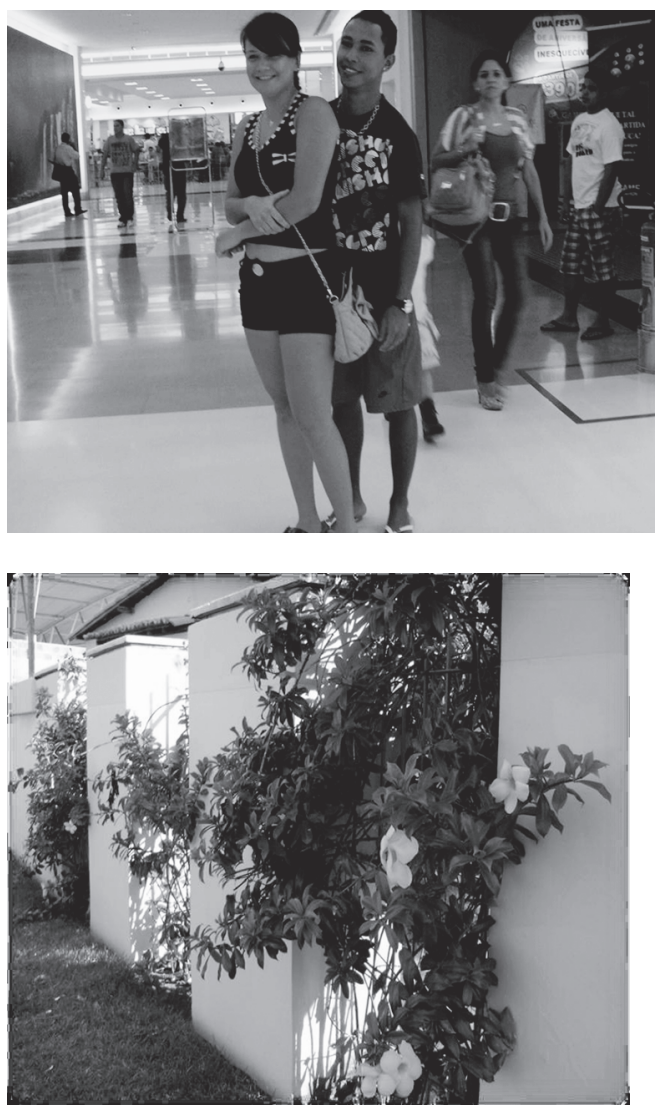

Sexualidade é ter compromisso, é noivar e casar, ter filho. É bom namorar e casar, até morrer. - Joyce, 16 anos. (Silva \& Oliveira, 2011, p. 92)

Figura 8. Fotografia de sexualidade: Joyce, 16 anos. Fonte: Silva, G. O. \& Oliveira, R. F. (2011). Escutando a surdez: signos e produção de sentidos por adolescentes surdos (p. 92). Trabalho de Conclusão de Curso, Curso de Psicologia, Universidade Potiguar Laureate International Universities, Natal, RN.

\section{É como essa planta aqui, a planta vive, cai a folha e a velhice da gente, quando vai chegando a planta vai caindo (risos) $E$ as flor vivendo. É o amor que nunca se acaba, né? $\mathrm{O}$ amor, o amor da gente, eu creio que nunca se acaba e a gente morre e nunca se acaba que fica na lembrança de quem nos ama. Assim a gente vai vivendo, feliz daquele que fica velho, feliz daquele que ama e tem amor né? - Adélia, 75 anos. (Pereira \& Sales, 2011, p 78)}

Figura 9. Fotografia de Sexualidade, Adélia, 75 anos. Fonte: Pereira, E. L. \& Sales, F. G. de M. (2011). (Re)tratando a velhice e a sexualidade na terceira idade: um registro fotográfico. (p.78) Trabalho de Conclusão de Curso, Curso de Psicologia, Universidade Potiguar - Laureate International Universities, Natal, RN.

Entre os idosos, também surgiu essa concepção assim fotografada e falada: representando um discurso uniformizado à cultura, obtivemos produções de fotografias e sentidos de sexualidade atrelados à genitalidade. Em contrapartida, em outros estudos (Mucida, 2004 citada por Pereira \& Sales, 2011) sobre sexualidade observamos que esta não se encontra apenas restrita às funções biológicas, genitais, mas que pode se apresentar de diversas maneiras ao longo da existência do sujeito conforme discursos e fotografias nas pesquisas de Pereira e Sales (2011) e de Silva e Oliveira (2011).

\section{Considerações finais}

Ao longo de dez anos, diversos pesquisadores e participantes estiveram envolvidos com o modo de fazer pesquisa que chamamos de ensaio fotográfico. Desde o trabalho com crianças e adolescentes no lixão, em 2002, vimo-nos envolvidas com um modo de investigar e produzir conhecimentos em Psicologia que está para além de um procedimento com caráter universalizante, de busca do comum, do homogêneo, de generalização e verdade. Propomos uma estratégia dos encontros singulares, das sutilezas, de produção de traços, de diferenças, de particularidades, de expressão da diversidade e movimento das subjetividades, proposta alinhada à perspectiva de Fonseca, Moehlecke e Neves (2010) quando se referem às tecnologias do sensível. 
Consideramos que as fotografias e as falas produzidas precisam ser compreendidas a partir dos signos emanados da conjuntura econômica, histórica, política, enfim, da cultura. Mas, consideramos que há formas distintas dessa conjuntura se apresentar, ou seja, sempre é preciso operar uma contextualização específica e transitória, no sentido de um perspectivismo radical (Gomes \& Dimenstein, 2005).

As produções daí originadas trazem uma proliferação de questões afetando tanto os pesquisadores quanto os participantes convidados à produção. Percebemos a boa receptividade do método tanto pelos pesquisadores que se disponibilizaram a usálo quanto dos participantes.

Um dos objetivos do ensaio fotográfico é promover criações e não verdades cristalizadas em um discurso linear e modelizado. Buscamos promover outros modos de narrar e interpretar a realidade. Aplicamos ao ensaio fotográfico as palavras Zambenedetti e Silva (2011) quando dizem que cartografia viabiliza

(...) a problematização da posição do pesquisador e do ato de pesquisar, onde a pesquisa é tomada como um campo de experimentação, atravessado pelo regime da sensibilidade. Não existe um campo constituído a priori e um pesquisador neutro em relação a ele, operando uma "coleta de dados" - como se os dados estivessem prontos, esperando o momento 'certo' para serem coletados. A coleta de dados só pode ser operada no encontro entre o pesquisador, suas ferramentas conceituais e o campo, encontro esse que pode modificar tanto o pesquisador quanto apontar os caminhos possíveis para a constituição de um campo. (p. 457)

Da pesquisa com profissionais de saúde ficou evidenciado por Medeiros e Be- zerra (2011) que o objetivo foi alcançado no sentido de promover inquietações tanto nos profissionais de saúde quanto nelas próprias pesquisadoras, permitindo o exercício da reflexão acerca dos signos acolhimento e humanização. Na medida em que afeta diretamente o pesquisador se coloca mais uma diferença entre essa estratégia de fazer pesquisa e alguns métodos que se pretendem neutros. Assim,

Intervir sobre o pesquisador é uma das nuances do método: Relembrar cada inserção a campo, os contatos com os idosos, dos momentos ímpares durante a pesquisa, possibilita o resgate de um turbilhão de afetos positivos, como também a sensação de que não somos os mesmos. Muito rico, significativo e emocionante cada discurso, cada olhar, cada abraço, cada registro fotográfico. (Pereira \& Sales, 2011, p. 83)

Almeida e Lourenço (2007) citados por Pereira e Sales (2011) destacam que o assunto da sexualidade na velhice é desprezado pelos profissionais de saúde, como também incompreendido pelos próprios idosos. Desse modo, pesquisas como estas contribuem sobremaneira para a produção do conhecimento na área da Psicologia e Saúde Coletiva, sobretudo pela valorização da produção dos idosos acerca do próprio ciclo de vida, como também dos aspectos coletivos e singulares que o envolve. Ademais, o processo dessa produção de evidências pode contribuir para a avaliação da atenção à saúde, da produção de saúde, tendo como protagonistas os próprios usuários do sistema de saúde, conforme assevera Bosi e Gastaldo (2011).

As resistências ao método foram poucas em relação à boa adesão dos participantes. $\mathrm{O}$ ensaio fotográfico encontrou alguma resistência entre os idosos evidenciada no seguinte discurso: "Meu filho eu não gosto 
dessas coisas não" (Pereira \& Sales, 2011, p. 50) e entre meninas do assentamento habitacional irregular: (...) num sei tirar foto não; há é só para tirar foto, quero não; não gosto dessas coisas não, "é por que agora eu tô toda desarrumada..." (Freitas \& Vasconcelos, 2004 , p. 78). Ademais, as resistências iniciais logo se desfaziam e davam lugar à produção de fazeres e reflexões.

Percebemos que a nossa proposta aproximase das produções que promovem a revelação de invisíveis por meio de imagens e discursos. Singularmente, foi possível observar o quanto a proposta pode se adequar ao estudo e protagonismo de pessoas e ou grupos diferenciados, atendendo a vários objetivos e desenhos de pesquisa. Nesse sentido, Silva e Oliveira (2011) apontam que o ensaio fotográfico com as adequações realizadas por elas proporcionou uma forma de

Valorização da Identidade Surda à medida que possibilitou retratar suas percepções através daquilo que representa sua maior expressão: a experiência visual, valorizada não apenas nos registros icônicos, mas também em suas narrativas expressas através da Libras (...) viabilizaram aos sujeitos pesquisados uma participação ativa neste estudo, onde não mais o ouvinte discursou sobre o surdo, mas o próprio surdo sinalizou sobre si, não estando sujeita a possíveis influências advindas da participação de um mediador intérprete entre os participantes e as pesquisadoras. (pp. 106-107)
O ensaio fotográfico pode ser entendido, dessa maneira, como uma ferramenta de pesquisa-intervenção com grande potencial na Psicologia, no complexo estudo da produção de subjetividades e produção do conhecimento a partir de modelos colaborativos e participativos também na Saúde Coletiva. Trata-se de uma estratégia aberta à produção de diferentes interpretações da realidade, sempre a partir das vivências de cada sujeito, viabilizando a reflexão do cotidiano a partir de elementos não discursivos, podendo ser utilizada em composição com outras opções metodológicas, enriquecendo, por fim, a caixa de ferramentas do pesquisador. Além disso, pode produzir interferência no plano das habilidades e competências dos participantes a partir do manejo de equipamentos até então desconhecidos, tendo, dessa maneira, um importante componente lúdico, que aproxima produção de conhecimento acadêmico e produção de conhecimento popular, produzindo empoderamento. Segundo Fonseca et al. (2010),

(...) Uma pesquisa assim concebida, sem a pretensão de descobrir ou revelar uma realidade ou um objeto dado, torna-se um poderoso, mas despretensioso, método de produção/invenção de conhecimento. E na medida em que se faz ciente da infinidade pulsante no plano de imanência, transforma-se em atrator de virtualidades que pedem passagem. (p.176) 


\section{Maria Aparecida de França Gomes}

Doutoranda em Psicologia pela Universidade Federal do Rio Grande do Norte, RN - Brasil.

E-mail: cidafrance@gmail.com

\section{Magda Dimenstein}

Doutora em Psiquiatria e Saúde Mental pela Universidade Federal do Rio de Janeiro, RJ Brasil. Docente da Universidade Federal do Rio Grande do Norte, RN - Brasil.

E-mail: magda@ufrnet.br

Endereço para envio de correspondência:

Av. Engenheiro Roberto Freire. CEP: 59.000-000. Natal - RN.

Recebido 02/06/2013, Aprovado 16/10/2013. 
Ariès, P. (2006). História social da criança e da família. Rio de Janeiro: LTC.

Bosi, M. L. M. (2012). Pesquisa qualitativa em saúde coletiva: panorama e desafios. Ciência \& Saúde Coletiva, 17(3):575586. doi: 10.1590/S1413-81232012000300002

Bosi, M. L. M., \& Gastaldo, D. (2011). Construindo pontes entre ciência, política e práticas em saúde coletiva. Revista Saúde Pública, 45(6):1197-200. doi: $\quad 10.1590 / S 0034-$ 89102011000600023

Charbonneau, P. E. (1980). Adolescência e liberdade. São Paulo: EPU.

Dinklage, R. I., \& Ziller, R. C. (1989). Explicating cognitive conflict through photo-communication. Journal of Conflict Resolution, 33(2), 309-317.

Fonseca, T. M. G., Costa, L. A., Moehlecke, V., \& Neves, J. M. (2010). O delírio como mé-todo: a poética desmedida das singularidades. Estudos e Pesquisas em Psicologia, UERJ, 10(1), 169-189. Recuperado de: www.pepsic.bvsalud.org.

Freitas, A. B., \& Vasconcelos, A. (2004). (Re)tratando a adolescência: produção de sentidos por adolescentes moradores de um assentamento habitacional irregular da cidade do Na-tal. Trabalho de Conclusão de Curso, Curso de Psicologia, Universidade Potiguar - Laureate International Universities, Natal, RN.

Freitas, J. L. (2010). Os signos "adolescência" e "tratamento" através da percepção dos adolescentes usuários de substâncias psicoativas. Trabalho de Conclusão de Curso, Curso de Psicologia, Universidade Potiguar - Laureate International Universities, Natal, RN.

Gomes, M.A.F. (2002). Trabalho Infantil e Risco à Saúde: Signos produzidos por Crianças e Adolescentes Trabalhadores no Lixão de Cidade Nova, Natal-RN. Dissertação de Mestra-do, Programa de Pós Graduação em Psicologia, Universidade Federal do Rio Grande do Norte, Natal, RN.
Gomes, M.A.F., \& Dimenstein, M. (2006). Subjetividade e narrativas visuais: a fotografia como recurso metodológico na pesquisa com crianças e adolescentes no campo da psicolo-gia. Vivencia (UFRN), 29, 409-427. Recuperado de http://www.cchla.ufrn.br/Vivencia/suma rios/29/PDFINTERNET_29/3_DOSSIA_i magens/CAP07_MARIĀAPARECIDAEMA GDADIMENSTËIN.pdf

Kossoy, B. (2000). Realidades e ficções na trama fotográfica. São Paulo: Ateliê Editorial.

Medeiros, A. S., \& Bezerra, R.V.A. (2011) O acolhimento à família na Unidade de Terapia Intensiva: a percepção de uma equipe multiprofissional. Trabalho de Conclusão de Curso, Curso de Psicologia, Universidade Potiguar Laureate International Universities, Natal, RN.

Monteiro, J. M. C., \& Dollinger, S. J. (1996). Estudo etnográfico e autofotográfico do menino na rua em Fortaleza, Ceará. Coletâneas da ANPEPP - Associação Nacional de Pesquisa e Pós-Graduação em Psicologia, 1(12), 45-60.

Neiva-Silva, L., \& Koller, S.H. (2002). O uso da fotografia na pesquisa em psicologia. Estudos de Psicologia, 7(2), 237-250. doi: $10.1590 / S 1413$ 294X2002000200005.

Penha, M. G. G., \& Lima, M. S. (2012). Retratando a história do serviço integrado de psico-logia (SIP) da Universidade Potiguar - UnP. Trabalho de Conclusão de Curso, Curso de Psicologia, Universidade Potiguar Laureate International Universities, Natal, RN.

Pereira, E. L., \& Sales, F. G. de M. (2011). (Re)tratando a velhice e a sexualidade na terceira idade: um registro fotográfico. Trabalho de Conclusão de Curso, Curso de Psicologia, Universidade Potiguar Laureate International Universities, Natal, RN.

Rosolato, G. (1988). Elementos de interpretação. São Paulo: Editora Escuta. 
Silva, G. O., \& Oliveira, R. F. (2011). Escutando a surdez: signos e produção de sentidos por adolescentes surdos. Trabalho de Conclusão de Curso, Curso de Psicologia, Universidade Potiguar - Laureate International Universities, Natal, RN.

Spink, M. J. P., \& Menegon, V. M. (2000). A Pesquisa como prática discursiva: superando os horrores metodológicos. In M. J. P. Spink, (Org.), Práticas discursivas e produção de sen-tidos no cotidiano: aproximações teóricas e metodológicas. (2a ed., pp 63-92). São Paulo: Cortez.

Spink, M. J. P. (Org.). (2000). Práticas discursivas e produção de sentidos no cotidiano: aproximações teóricas e metodológicas. (2a ed.). São Paulo: Cortez.
Tacca, F. (2005). Imagem fotográfica: aparelho, representação e significação. Psicologia \& Sociedade, 17(3), 9-17. doi: 10.1590/S0102-71822005000300002.

Zambenedetti, G., \& Silva, R. A. N. (2011). Cartografia e genealogia: aproximações possíveis para a pesquisa em psicologia social. Psicologia \& Sociedade; 23(3), 454-463. doi: 10.1590/S010271822011000300002

Ziller, R. C., \& Smith, D. E. (1977). A phenomenological utilization of photographs. Journal of Phenomenological Psychology, 7(2), 172182. doi: $10.1163 / 156916277 \times 00042$ 